\title{
A COMPARATIVE STUDY OF INCENTIVE MECHANISMS USED IN PEER-TO-PEER SYSTEM
}

\author{
GURUPRASAD KHATANIAR ${ }^{1}$, SANKHAPANI BHARALI ${ }^{2}$ AND ARCHANA \\ KHATANIAR $^{3}$ \\ ${ }^{1}$ Department of Computer Engineering, Assam Engineering Institute, Assam, \\ India \\ drkhataniaregmail.com \\ ${ }^{2}$ Department of Computer Engineering, Girls' Polytechnic, Assam, India \\ sankhapb@yahoo.co. in \\ ${ }^{3}$ Department of Mathematics, Bajali College, Assam, India \\ archanakhataniar@gmail. com
}

\begin{abstract}
Incentive mechanism tells how to encourage nodes in a peer-to-peer system to contribute their resources. A peer avoids contributing resources to the $22 p$ system because of the factors like: cost of bandwidth, security reason as it has to open several ports in order to allow others to take out its resources and slowing down of self downloading process. In this paper we present a comparative study on some incentive models after going through several research papers in the line. A few models are implemented to show the simulation results. Finally conclusion is made by identifying the best incentive mechanism for p2p system and improvements are suggested based on the findings.
\end{abstract}

\section{KEYWORDS}

P2P, Incentive mechanism, Free-rider, White-washing.

\section{INTRODUCTION}

The peer-to-peer system is increasingly popular amongst internet users due to its nature of resource sharing ability, in which every peer node is contributing its resources to the network as well as consumes resources contributed by other peers. At the same time attacks on $\mathrm{p} 2 \mathrm{p}$ networks also increased which become the threats to the existence of $\mathrm{p} 2 \mathrm{p}$ system. The most common attacks are: free-riding and white-washing. Free-riders are peers in P2P network which do not contribute any resources but consume resources freely from the network. White-washers are freeriders which frequently leave the system and re-appear with a different identity to get-rid-of penalties imposed by the network. In addition to these, some more attacks are: sybil-attack and malicious behavior of peers. In sybil attack [8], when an attacker entered into a system it creates a large number of identities in order to gain influence over the $\mathrm{p} 2 \mathrm{p}$ system. The malicious behavior of peers says that a few number of peers may grouped together to cheat the system by increasing each others' points or grades within their small group.

Natarajan Meghanathan, et al. (Eds): ITCS, SIP, JSE-2012, CS \& IT 04, pp. 151-159, 2012. 
The existing incentive mechanisms can be classified into three categories such as schemes based on inherent generosity, monetary-based and reciprocity $[1,5]$.

In schemes based on inherent generosity every user decides whether to contribute or free-ride based on how its generosity compares to the current contribution cost in the system. If the social generosity is below a threshold level, then numbers of free-riders are more and the system collapses. But if it exceeds the threshold limit, the contribution level increases with diminishing returns. For example warm-glow model which was based on inherent generosity, but it was not successful because it fails to explain the observed behavior of peer. Another example is the modeling framework that has been devised by M. Feldman et al. [6] that studies the phenomenon of free-riding in P2P systems while taking user generosity into account.

In monetary-based schemes the service recipients simply pay for resources they consume. Monetary schemes allow for rich economic mechanisms based on accounting and microeconomic infrastructures. Drawbacks of monetary-based schemes are: individual costs of service providers may be hidden from the service recipient, actions of the service providers may be hidden from the service recipient and delivery of payment from the recipient to the service providers is a problem. For the solution of the third problem schemes are proposed based on virtual currency.

In reciprocity-based schemes users maintain behavior histories of other users and use this information in their decision making processes. These schemes can be based on direct reciprocity or indirect reciprocity. In direct-reciprocity schemes, a user serves another user based on services it received from that peer in past. Example of direct reciprocity is a BitTorrent [9] file-distribution system, which employs a tit-for-tat incentive mechanism to encourage cooperative behavior between a set of nodes performing coordinated exchange of large digital files. In indirectreciprocity schemes, a user serves another user on basis of services that the peer has provided to other users in the system in addition to that user. Several indirect-reciprocity schemes have been proposed in the literature, and they are often called reputation-based schemes. They differ from one another primarily in computation of reputation scores and the mapping of scores to strategies.

\section{Analysis of Different Methods}

In this paper, four research papers are considered for comparative study which are G. Khataniar et al. [2], E. Anceaume et al. [3], M. Yang et al. [4] and S. M. Lui et al. [7]. These are referred as model-1, model-2, model-3 and model-4, respectively throughout this paper.

To compare the models some of the features are considered such as handling free-riding and white-washing, type of incentive mechanism, registration policy, resource sharing, query processing, load balancing, and underlying peer-to-peer model. The comparisons are shown in Table-1.

Table 1. Comparison of four models: model-1, model-2, model-3 and model-4

\begin{tabular}{|l|l|l|l|l|}
\hline \multicolumn{1}{|c|}{ Features } & Model 1 & Model 2 & Model 3 & Model 4 \\
\hline $\begin{array}{l}\text { Handling free- } \\
\text { riding and white- } \\
\text { washing problem }\end{array}$ & $\begin{array}{l}\text { Efficiently } \\
\text { handled }\end{array}$ & Handled properly & $\begin{array}{l}\text { Free-riding is } \\
\text { handled, white- } \\
\text { washing is } \\
\text { identifiable but } \\
\text { allowed. }\end{array}$ & $\begin{array}{l}\text { Free-riding and } \\
\text { white-washing is } \\
\text { not possible } \\
\text { normally }\end{array}$ \\
\hline $\begin{array}{l}\text { Concepts of } \\
\text { incentive } \\
\text { mechanism } \\
\text { applied }\end{array}$ & $\begin{array}{l}\text { By means of } \\
\text { grading system, } \\
\text { providing access } \\
\text { according to }\end{array}$ & $\begin{array}{l}\text { Cooperative peers } \\
\text { are rewarded and } \\
\text { non-cooperative } \\
\text { peers are }\end{array}$ & $\begin{array}{l}\text { Uploading } \\
\text { increases points, } \\
\text { downloading } \\
\text { decreases points. }\end{array}$ & $\begin{array}{l}\text { Contributors are } \\
\text { rewarded by } \\
\text { tangible or } \\
\text { intangible means. }\end{array}$ \\
\hline
\end{tabular}




\begin{tabular}{|c|c|c|c|c|}
\hline & contribution level. & punished. & & $\begin{array}{l}\text { Peers evaluation } \\
\text { is done by peer's } \\
\text { recommendations. }\end{array}$ \\
\hline $\begin{array}{l}\text { Registration } \\
\text { policy }\end{array}$ & $\begin{array}{l}\text { Through Stable } \\
\text { Node and Fully } \\
\text { Stable Node }\end{array}$ & $\begin{array}{l}\text { Through } \\
\text { registration } \\
\text { service }\end{array}$ & $\begin{array}{l}\text { Through Maze } \\
\text { central server }\end{array}$ & $\begin{array}{l}\text { Through a central } \\
\text { authority called } \\
\text { identification } \\
\text { system }\end{array}$ \\
\hline Resource sharing & $\begin{array}{l}\text { Normal Nodes } \\
\text { upload its file } \\
\text { indices to its } \\
\text { Stable Nodes. } \\
\text { Stable Nodes } \\
\text { upload its file } \\
\text { indices to its } \\
\text { Fully Stable } \\
\text { Nodes }\end{array}$ & $\begin{array}{l}\text { Each different } \\
\text { resource of the } \\
\text { peers are } \\
\text { organized in } \\
\text { different semantic } \\
\text { groups headed by } \\
\text { different } \\
\text { supervisors }\end{array}$ & $\begin{array}{l}\text { File indices of } \\
\text { peers are kept in } \\
\text { central server. } \\
\text { Peers shares some } \\
\text { load using } \\
\text { friend's/ } \\
\text { /neighborhood/ } \\
\text { reputed peers } \\
\text { lists. }\end{array}$ & $\begin{array}{l}\text { Central server } \\
\text { keeps the file } \\
\text { indexes of all the } \\
\text { peers. Sub } \\
\text { communities are } \\
\text { formed to share } \\
\text { some loads }\end{array}$ \\
\hline Query processing & $\begin{array}{l}\text { Query made by a } \\
\text { node of a } \\
\text { particular grade is } \\
\text { meeting-up by } \\
\text { contents from } \\
\text { nodes of same or } \\
\text { below grade peers } \\
\text { belonging either } \\
\text { to same LAN, or } \\
\text { to same group or } \\
\text { entire system. }\end{array}$ & $\begin{array}{l}\text { A peer can make } \\
\text { a query directly to } \\
\text { another peer, } \\
\text { which holds the } \\
\text { contents. Peer } \\
\text { gets this } \\
\text { information from } \\
\text { the supervisors of } \\
\text { the semantic } \\
\text { groups. }\end{array}$ & $\begin{array}{l}\text { Normally peers } \\
\text { made query to } \\
\text { central server. } \\
\text { Gradually queries } \\
\text { may meet up by } \\
\text { different lists } \\
\text { maintained by the } \\
\text { peers. }\end{array}$ & $\begin{array}{l}\text { Query is made to } \\
\text { the central server. } \\
\text { There are sub- } \\
\text { communities for } \\
\text { marketing and } \\
\text { advertisement } \\
\text { purpose which } \\
\text { helps the servers. }\end{array}$ \\
\hline Load balancing & $\begin{array}{l}\text { Load balancing is } \\
\text { properly done }\end{array}$ & Not considered & $\begin{array}{l}\text { Load balancing is } \\
\text { done in a partial } \\
\text { manner }\end{array}$ & $\begin{array}{l}\text { Load balancing is } \\
\text { done in a partial } \\
\text { manner }\end{array}$ \\
\hline $\begin{array}{l}\text { Underlying } \mathrm{p} 2 \mathrm{p} \\
\text { model }\end{array}$ & $\begin{array}{l}\text { Unstructured } \\
\text { Hybrid p2p }\end{array}$ & $\begin{array}{l}\text { Unstructured pure } \\
\text { p2p }\end{array}$ & $\begin{array}{l}\text { Unstructured } \\
\text { Centralized p2p }\end{array}$ & $\begin{array}{l}\text { Unstructured } \\
\text { Centralized p2p }\end{array}$ \\
\hline
\end{tabular}

\section{Advantages and Limitations of the Models}

Advantages and limitations of the incentive mechanisms discussed in section are summarized below:

1. Model-1: It has advantages that it can handle free-riding, white-washing, group-cheating and load balancing properly. Also it has a mechanism to stabilize the system. But it has limitations as it is silent about sybil attack.

2. Model-2: It has advantages that it can handle free-riding and white-washing properly. But it has limitations as it cannot resist group-cheating, it has no proper load balancing and it is silent about sybil attack.

3. Model-3: It has advantages as it can handle free-riding and white-washing properly and can resist sybil-attack too. But it has limitations as it is vulnerable to single point of failure. It will slow down in time due to the presence of centralized components.

4. Model-4: It has advantages as it can identify the type of a peer. Though free-riding can be detected easily, yet they are allowed up to some extent till the system allowed. White-washing 
and sybil-attacks are not possible in this model. It has certain limitations as it is vulnerable to single point of failure. It will slow down in time due to the presence of centralized server. The overloading of central server may lead to slow down the performance of the system. The congestion may occur near the traffic of central server which might lead to collapse of the system.

From the above discussion it is seen that model-3 and model-4 has severe shortcoming. Both of them uses centralized component, which lead to single point of failure. From the architectural point of view also they are weaker, they cannot resist current increasing load of internet. However in spite of those limitations they have some potential advantages which will be helpful in designing a better integrated model. Therefore these two models are dropped from further implementation. Hence only model- 1 and model- 2 are implemented and results are discussed in the section-IV.

\section{Experiment Results}

The model-1 and model-2 are implemented in java platform and simulated results are compared on basis of some common parameters.

In this experiment both models are simulated over same number of iterations and we consider the number of iteration to be 10,000 where 10,000 events are performed. The performance the system is measured on basis of the behavior of joining of new peer, uploading of resources, and query executed.

1. Results of Model-1: The system is implemented to execute any one operation in each iteration. The output is taken after 1000 iterations. The simulation results are shown in Table-2 and Table3. The Figure-1 and Figure-2 represents Event-Grade graph and Event-Query graph, respectively. In Figure-1, it is seen that during bootstrapping period 672 peers are available and all are at grade- 0 . Therefore, there are no peers with grade- 1 and grade- 2 at event 0 . Ideally number of grade- 0 peers should be decreased as some of them are turning into grade- 1 and grade- 2 . But it is not so because of joining of new peers in the system. Hence it is seen that grade- 0 peers is decreased up to a point during event numbers 3000 to 4000 and after that it starts increasing. Though the number of grade- 1 and grade- 2 peers are initially 0 , these are gradually increased. A peer with a higher grade has higher access, so every peer tries to place them in higher grade. This fact can be observed from the graphs. It is observed that grade- 2 is increasing sharply which implies that the system provides incentives accordingly. In Figure-2, the graph shows the number of queries failed and successful. Failure of queries may occur mainly because the grade value of querier node is less than the grade value of resource holder. The other reason is the resource is not available. Less number of query failures indicates proper functioning of incentives.

Table 2. Number of peers with grade-0, grade-1 and grade-2 after each 1000 iterations

\begin{tabular}{|c|c|c|c|}
\hline Number of Events & $\begin{array}{c}\text { Number of peers } \\
\text { with grade-0 }\end{array}$ & $\begin{array}{c}\text { Number of peers } \\
\text { with grade-1 }\end{array}$ & $\begin{array}{c}\text { Number of peers } \\
\text { with grade-2 }\end{array}$ \\
\hline 0 & 672 & 0 & 0 \\
\hline 1000 & 450 & 200 & 351 \\
\hline 2000 & 353 & 294 & 676 \\
\hline 3000 & 308 & 343 & 980 \\
\hline 4000 & 308 & 377 & 1289 \\
\hline 5000 & 340 & 423 & 1559 \\
\hline 6000 & 374 & 480 & 1801 \\
\hline 7000 & 414 & 536 & 2047 \\
\hline
\end{tabular}




\begin{tabular}{|c|c|c|c|}
\hline 8000 & 445 & 595 & 2291 \\
\hline 9000 & 491 & 653 & 2498 \\
\hline 10000 & 540 & 713 & 2734 \\
\hline
\end{tabular}

Table 3. Number of Queries successful or failed during each 1000 iterations

\begin{tabular}{|c|c|c|}
\hline Number of Events & Number of Query Success & Number of Query Failed \\
\hline 1000 & 319 & 3 \\
\hline 2000 & 658 & 9 \\
\hline 3000 & 992 & 14 \\
\hline 4000 & 1322 & 16 \\
\hline 5000 & 1652 & 18 \\
\hline 6000 & 1972 & 20 \\
\hline 7000 & 2289 & 20 \\
\hline 8000 & 2619 & 21 \\
\hline 9000 & 2947 & 22 \\
\hline 10000 & 3295 & 23 \\
\hline
\end{tabular}

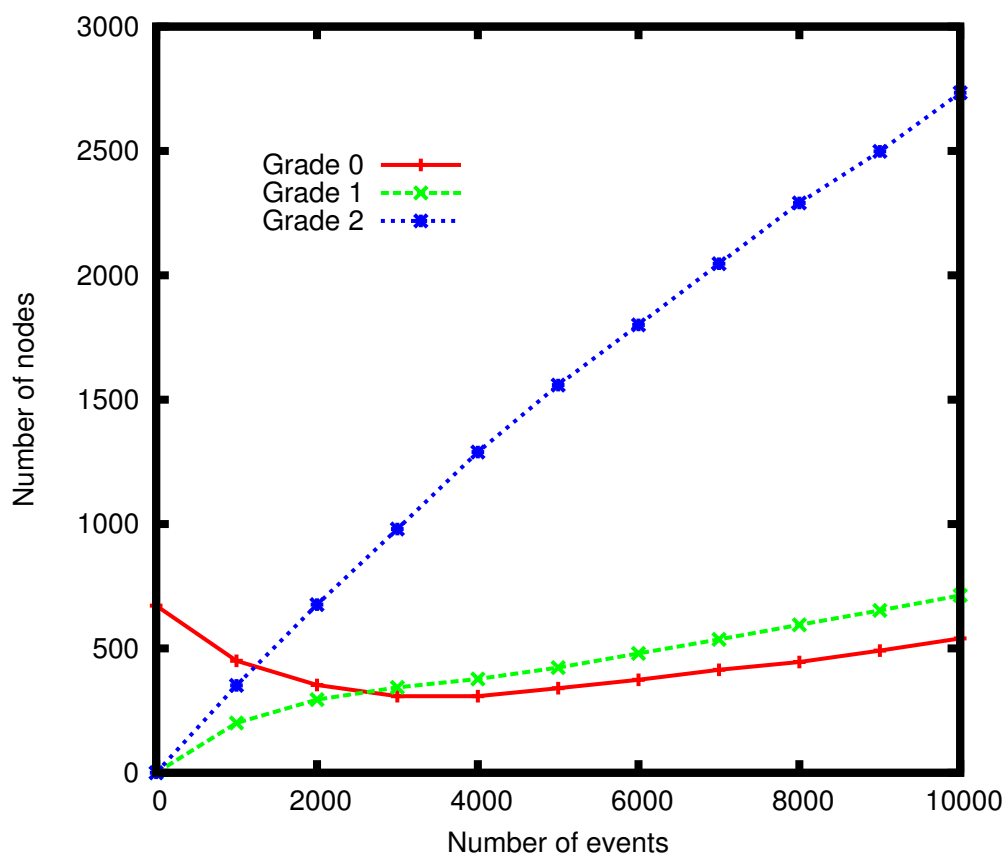

Figure 1. Event-Grade graph for model-1

2. Results of Model-2: The set of results is taken after 1000 iterations. In this case a query may fail not only for unavailability of resources but due to the target peer which may not share resources. The Table-4 shows the number of peers at different access level. Access level increases when peer upload resources and resources of peer are requested by other peers. Depending upon points, the access level is categorized into three categories as shown in Table- 4 .

The graph shown in Figure-3 indicates different access level at different iterations. It is observed that initially all peers are at access level below 500. Gradually as access level increases the number of peers at next categories increases. The peers at below 500 points increases slowly as new peers join the system. It is observed that most of the peers earn higher access level over time 
which means proper incentives are exhibited by the system. The graph shown in Figure-4 indicates the number of peers whose queries are successful or failed. The query may fail due to the target peer might not be interested in sharing resources.

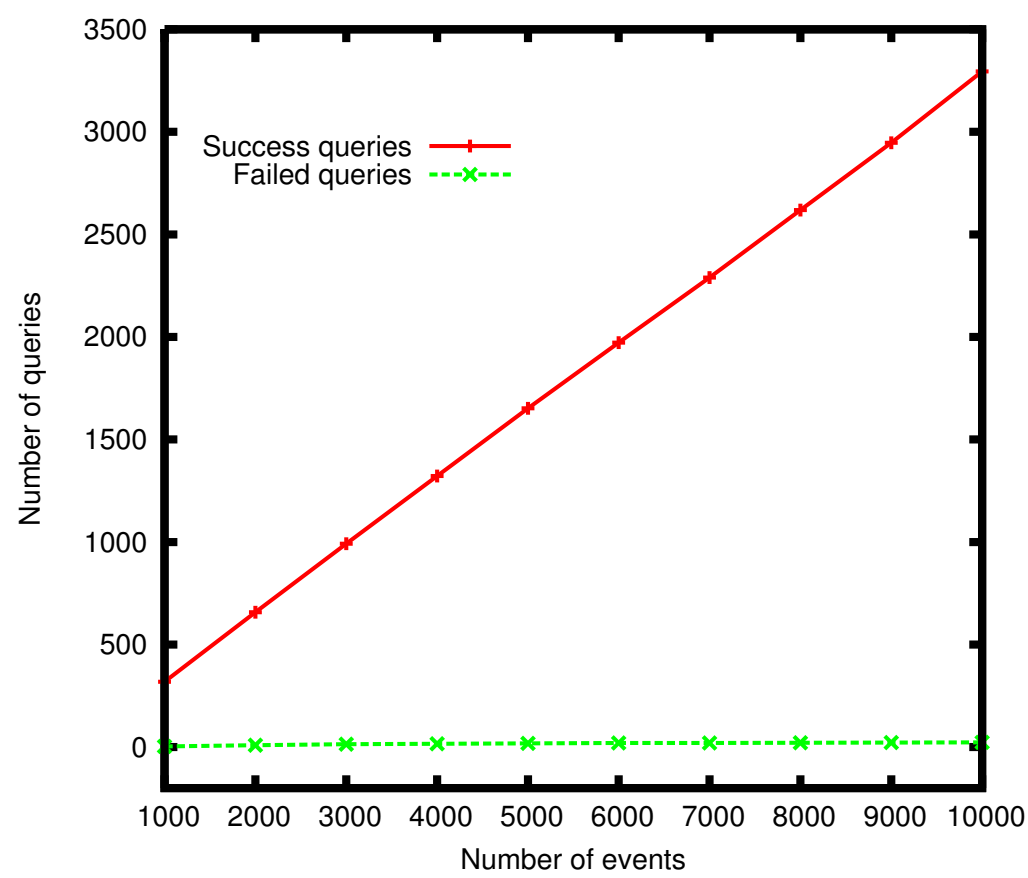

Figure-2. Event-Query graph for model-1

Table 4. Number of events and number of peers attaining access levels below 500 points, between 500 and 1000 points, more than or equal to 1000

\begin{tabular}{|c|c|c|c|}
\hline Number of Events & \multicolumn{3}{|c|}{ Access Level } \\
\cline { 2 - 4 } & Below 500 & $\begin{array}{c}\text { Between 500 and } \\
\mathbf{1 0 0 0}\end{array}$ & $\begin{array}{c}\text { Equal or more than } \\
\mathbf{1 0 0 0}\end{array}$ \\
\hline 0 & 512 & 0 & 0 \\
\hline 1000 & 377 & 82 & 254 \\
\hline 2000 & 318 & 117 & 485 \\
\hline 3000 & 293 & 150 & 686 \\
\hline 4000 & 288 & 178 & 854 \\
\hline 5000 & 289 & 204 & 1013 \\
\hline 6000 & 305 & 236 & 1162 \\
\hline 7000 & 323 & 256 & 1309 \\
\hline 8000 & 380 & 314 & 1615 \\
\hline 9000 & 404 & 357 & 1731 \\
\hline 10000 & 431 & 392 & 1792 \\
\hline
\end{tabular}




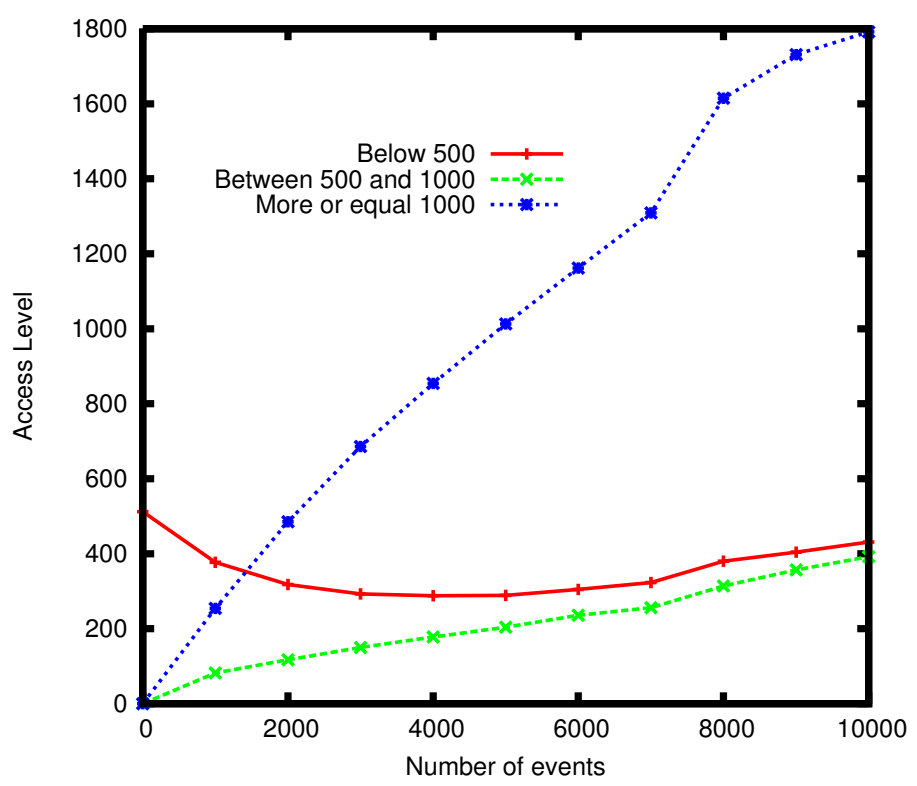

Figure-3. Access Level graph for model-2

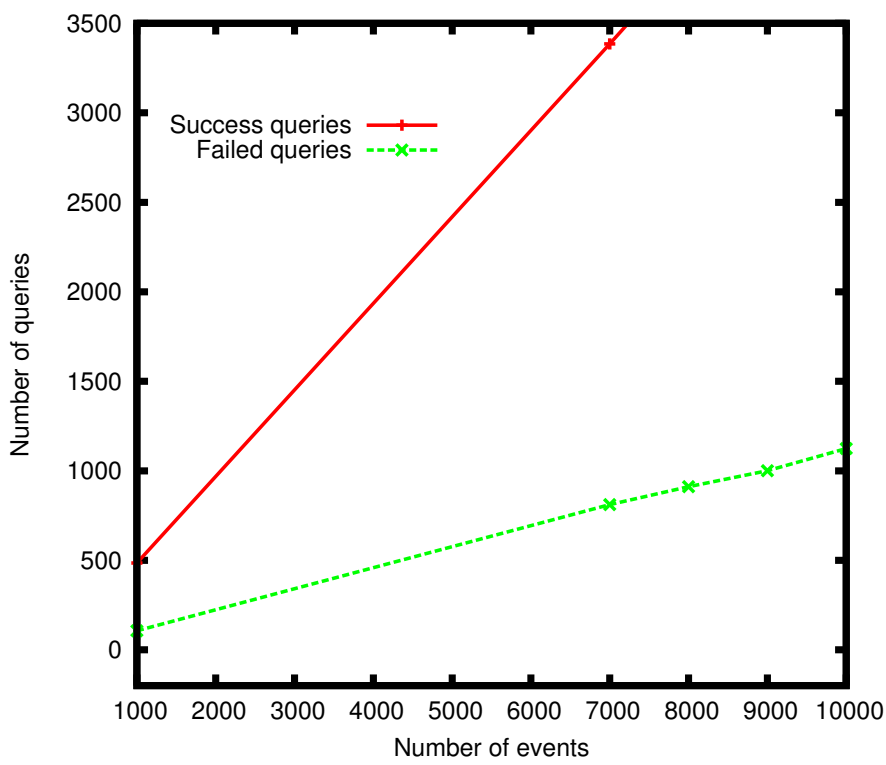

Figure 4. Event-Query graph for model-2

From the above discussion it is found that both model- 1 and model- 2 are satisfying the incentive criteria as referred in Figure-1 and Figure-3, respectively. But the percentage of query failed in model-2 is more than model-1 as shown in Figure-4 and Figure-2, respectively. The architecture of model-2 is such that query success also depends upon the behavior of the queried peer. Whether the queried peer gives response or discards the query, it decides the success or failure of the query. But in case of model-1, the architecture is such that if grade of the requestor node match the queried node and the resource is found then query is always satisfied. 


\section{CONCLUSIONS}

Implementation provides good comparison rather than direct analysis of models on basis of different parameters. A comparative study of model-1 and model-2 is presented on the basis of implementation on java platform. By observing the results it is concluded that model-1 is better due to the following facts.

- Architectural complexity of the model-1 is very less than the architectural complexity of model-2 which permits it to run faster.

- Criteria of meeting up of query are better in model-1 than model-2 which permits it to good query response.

A proper incentive mechanism will help in motivating the developers or contributors to enhance their DHT based P2P system. In future an integrated incentive model may be designed which will contain best features of both the models so that the attack can be reduced to a greater extent in order to motivate the peers to contribute to the system. It can provide new business opportunities in the newly emerging P2P technology applications.

\section{REFERENCES}

[1] M. R. Rahman, "A Survey of Incentive Mechanisms in Peer-to-Peer Systems," in University of Waterloo Technical Report CS-2009-22, June 2009.

[2] G. Khataniar, B. K. Shrivastava, S. K. Samudrala, G. B. Kumar, D. Goswami "A Hybrid Architecture for Unstructured Peer-to-Peer Systems" in International Journal of Information Processing, pp. 12 - 20, Volume 2, Issue 3, 2008.

[3] E. Anceaume, M. Gradinariu and A. Ravoaja, "Incentive For Peer-to-Peer Fair Resource Sharing," in Proceedings of the Fifth IEEE International Conference on peer-to-peer Computing (peer-to-peer'05), IEEE, May 2005.

[4] M. Yang, Z. Zhang, X. Li and Y. Dai, "An Empirical Study of Free-Riding Behavior in The Maze Peer-to-Peer File-Sharing System," in The 4th Annual International Workshop on Peer-To-Peer Systems (IPTPS'05), pp. 182-192, 2005.

[5] M. Feldman and J. Chuang, "Overcoming Free-Riding Behavior in Peer-to-Peer Systems," in ACM SIGecom Exchanges, Vol. 5, No. 4, pp. 41-50, ACM, July 2005.

[6] M. Feldman, C. Papadimitriou, J. Chuang and I. Stoica, "Free-Riding and Whitewashing in Peer-toPeer Systems,” in SIGCOMM’04 Workshop Portland, Oregon, USA, ACM, August 30, 2004.

[7] S. M. Lui, K. R. Lang, and S. H. Kwok, "Participation Incentive Mechanisms in Peer-to-Peer Subscription Systems," in Proceedings of the 35th Annual Hawaii International Conference on System Sciences (HICSS-35'02), IEEE September 2002.

[8] John R. Douceur, "The Sybil Attack," in the First International Workshop on Peer-to-Peer Systems (IPTPS '01), pp. 251-260, London, UK, 2002.

[9] B. Cohen, "Incentives to Build Robustness in Bittorrent," http://bitconjurer.org/BitTorrent/bittorrentecon.pdf. 


\section{Authors}

Dr. Guruprasad Khataniar has done his Bachelors in C.Sc \& Engg. from Jorhat Engineering College under Dibrugarh University, Assam. He has computed his M.Tech from IIT Delhi and Ph.D. from IIT Guwahati in C.Sc. \& Engg. He has 4 International Journal publications and more than 10 conference papers. Presently he is a senior faculty member of Computer Engineering Department at Assam Engineering Institute, Assam, India. His area of interest is Mathematical modelling and Distributed system

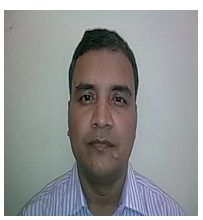

Mr. Sankha Pani Bharali has done his Bachelors in C.Sc \& Engg. from Jorhat Engineering College under Dibrugarh University, Assam. He has done M.Tech from NITTTR Chandigarh. Presently he is working as a faculty in Computer Enginee ring at Girls' Polytechnic, Assam. His area of interest is peer-to-peer networking and distributed system.

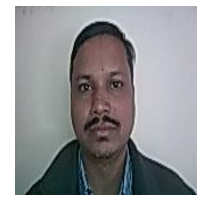

Mrs. Archana Khataniar has done her MSc in Mathematics and B.Ed. from Gauhati University, Assam. She an Assistant Professor in Mathematics Department at Bajali College, Pathsala. Her research interest is Mathematical Modelling of Computer Networking and Distributed System.

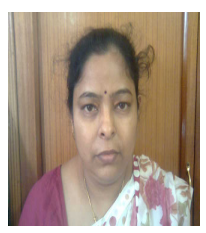

